\title{
Impact of a 'School-Based' Nutrition Intervention on Anthropometric Parameters and the Metabolic Syndrome in Spanish Adolescents
}

\author{
M.M. Campos Pastor ${ }^{a}$ M.D. Serrano Pardo ${ }^{a} \quad$ M.L. Fernández Soto ${ }^{a}$ \\ J.D. Luna del Castillo ${ }^{b}$ F. Escobar-Jiménez ${ }^{a}$ \\ ${ }^{a}$ Endocrinology and Nutrition Unit, University Hospital San Cecilio, and ${ }^{b}$ Department of Biostatistics, School of \\ Medicine, University of Granada, Granada, Spain
}

\section{Key Words}

Adolescents $\cdot$ Metabolic syndrome $\cdot$ Nutrition

intervention · Obesity $\cdot$ Overweight

\begin{abstract}
Background/Aims: In adolescents, overweight and obesity are associated with an increased cardiovascular risk. The aim of this study was to determine the impact of a school-based nutritional education program (NEP) on lifestyle changes in Spanish adolescents. Methods: We selected 263 secondary school students (127 males) aged 12-16 years from Granada (Spain), who were followed up throughout 1 school year (2009-2010). At the beginning and end of the school year, data were gathered on the food consumption frequency, and anthropometric and biochemical profile. The NEP comprised a class on nutritional recommendations every 15 days, and administration of a daily breakfast of 275-350 kcal. $\boldsymbol{R e}$ sults: After the intervention, the prevalence of overweight and obesity decreased among both male and female students $(p<0.001)$ and there was also a global reduction in the prevalence of the metabolic syndrome (MS) from 32.2 to $19.7 \%$ ( $p<0.001$ ); in addition, body mass index was significantly decreased in normal weight, overweight and obesity groups ( $p=0.001$ and $p=0.02$, respectively), and high-den-
\end{abstract}

sity-lipoprotein cholesterol and lean body mass was increased in all groups $(p=0.001)$. Conclusion: The NEP achieved a medium-term reduction in the prevalence of overweight and obesity and had a significant and positive effect on MS components in all groups.

Copyright $\odot 2012$ S. Karger AG, Basel

\section{Introduction}

The prevalence of obesity among children is rising in developed countries [1]. In many countries such as Spain, there is an elevated and increasing prevalence of childhood obesity and overweight. The EnKid study, which was conducted in Spain between 1998 and 2000, found that $26 \%$ of children and young people were overweight or obese, with a higher prevalence of obesity in males than in females [2]. Childhood obesity is known to be an independent risk factor for adult obesity [3]. Furthermore, a high body mass index (BMI) in childhood, especially from the age of 13 years, is associated with a higher risk of coronary disease in adulthood [4] and has also been associated with all-cause and cardiovascular mortality in adults [5].

\section{KARGER}

Fax +4161306 1234

E-Mail karger@karger.ch

www.karger.com
(C) 2012 S. Karger AG, Basel

$0250-6807 / 12 / 0614-0281 \$ 38.00 / 0$

Accessible online at:

www.karger.com/anm
$\mathrm{M}^{\mathrm{a}}$ Mar Campos Pastor

Urbanización Los Cerezos

Abedul no. 6

ES-18050 Gójar, Granada (Spain)

Tel. +34958249082, E-Mail campospastor@terra.es 
The increase in the prevalence of overweight and obesity has been accompanied by a rising prevalence of the metabolic syndrome (MS) among school-age children over the past 2 decades $[6,7]$. The short-term risk of MSrelated comorbidities and the longer-term risk of cardiovascular morbidity-mortality make this a matter of concern $[8,9]$.

There is strong evidence that childhood obesity is related to the energetic content of their diet and their sedentary lifestyle. Hence, there is a need for interventions designed to change these habits and reduce the risk of obesity. The school is the preferred setting for this type of program due to the intensive and continuous contact with the children and since it is able to provide the necessary infrastructure to exert an influence on childhood health $[10,11]$.

The main objective of this study was to assess the repercussion of a nutritional education program (NEP) on anthropometric variables, eating habits and MS components in adolescents.

\section{Subjects and Methods}

The study included individuals aged between 12 and 16 years (the age range of secondary education in Spain) recruited at educational centers in the city of Granada and outskirts. Granada is a city in southern Spain with 250,000 inhabitants and 90 secondary schools (69 public and 21 private). In the first phase of the study, we determined the prevalence of overweight and obesity and the dietary habits in adolescents from Granada. Based on a total population of 51,349 students, an estimated proportion of $14 \%$, precision of 1.5 and confidence interval of $95 \%$, we estimated a sample size of 2,372 adolescents. The school was the primary sampling unit and the class the final unit. Eleven public schools and 5 private schools were randomly selected, inviting a total of 2,568 students to participate. We obtained informed consent from the parents for 2,246 of them (1,102 males and 1,144 females).

For the study of the effects of the intervention (second phase), the sample size estimation was based on the prevalence study data; for an $\alpha$ risk of 0.05 and a $\beta$ risk of 0.20 , a sample size of 261 adolescents was estimated, assuming initial and final prevalence rates of overweight of 24 and 15\%, respectively, and losses to the study were $<10 \%$. Two schools ( 1 public and 1 private) were randomly selected from among the participating schools, and 5 classes were randomly selected from each school. Out of the $298 \mathrm{stu}-$ dents selected for NEP, written informed consent was obtained for 256: 127 males and 129 females, mean age $( \pm S D): 13.9$ ( \pm 1.4$)$ years. The research project was approved by the ethics committee of our hospital and was presented to the local education department, the directors and school council of each center, and the teachers and parents of the school students. A program of classes was conducted throughout the 2009-2010 school year, directed at the students, their family members (usually parents and occasionally grandparents) and their teachers. The classes focused on di- etary and lifestyle recommendations, with a well-balanced diet which contains: 5 portions/day of fruits and vegetables, 4 portions/day of dairy products and 4-6 portions/day of starchy food, e.g. bread, potatoes, pasta and rice. The weekly consumption did not exceed 2 daily portions of eggs, lean meat, fish, pulses, nuts and dried fruit, and only occasional eating of fatty meats, cold meats, cakes and sweets. The consumption of $1,500 \mathrm{ml}$ of nonfizzy, non-sugary drinks was recommended. The energy content of a healthy diet is in accordance with age and sex [12].

Other contents were: epidemiology of obesity and analysis of the nutritional factors that produce this disease during childhood and adolescence; misleading publicity and activity/inactivity (hours of daily screen time with TV, computer and internet). Fortnightly classes lasting $45 \mathrm{~min}$ were given by endocrinologists and nutrition specialists to the students in each class (25/30 students/ class), 1 or 2 family members per student and their teachers. Students, family members and teachers were together in these classes, but specific teaching material was developed for each group.

In this study, a questionnaire to measure physical activity, based on the long, self-report version of IPAQ (International Physical Activity Questionnaire) [13], was developed. This provides respondents with individualized feedback on their behavior in such a way that an appropriate individual response is facilitated and consolidated.

For the purpose of monitoring adherence to the prescribed diet, we used the 24-hour recall format as a standard method [14] every month in the intervention group. In the context of dietary lifestyle, we enforced a food culture based on 'foods to eat' rather than 'foods to avoid'.

The students received a daily breakfast at the school (MondayFriday) composed of a dairy product (milk or yoghurt), fruits, cereals, nuts and a sandwich with protein content (tuna or drycured or boiled ham); the total caloric value ranged from 275 to $350 \mathrm{kcal}$. Breakfast taking was monitored daily by project researchers and teachers at the schools.

At the beginning and end of the school year, the weight and height of participants were measured, and their BMI was calculated $\left(\mathrm{kg} / \mathrm{m}^{2}\right)$ They were classified as normal weight, overweight or obese according to the BMI cutoff values proposed by Cole et al. [15]. Waist circumference (WC) was measured with a flexible steel tape at the narrowest point between the lower costal border and the iliac crest [16]. At the same time, impedance measurements were performed using a model TBF-300 Tanita body composition analyzer [17] in a standardized way for the study of body composition. The impedance measurements have to be taken after $2 \mathrm{~h}$ of fasting and after at least 8-12 $\mathrm{h}$ of strenuous exercise or other factors that could affect hydration [18].

Morning blood samples were drawn by standard venipuncture technique after overnight fasting. Samples were kept on ice and sent to the project laboratory for analysis. Plasma glucose was measured by the glucose oxidase method. Triglycerides were measured enzymatically (Menarini Diagnostic, Florence, Italy) with an RA-1000 AutoAnalyzer (coefficient of variation of 3.42\%). High-density-lipoprotein cholesterol (HDL-c) was also assessed with the RA-1000 AutoAnalyzer after precipitation of apolipoprotein-B-containing lipoproteins with phosphotungstic acid and Mg (Roche Diagnostics, Barcelona, Spain). After a 5 -min rest, blood pressure (BP) readings were taken at 2-min intervals, using an Omron M5-1 automatic sphygmomanometer [19] with three cuffs of different arm circumference sizes (17-22, 
Fig. 1. Follow-up protocol for the whole study group and the intervention group.

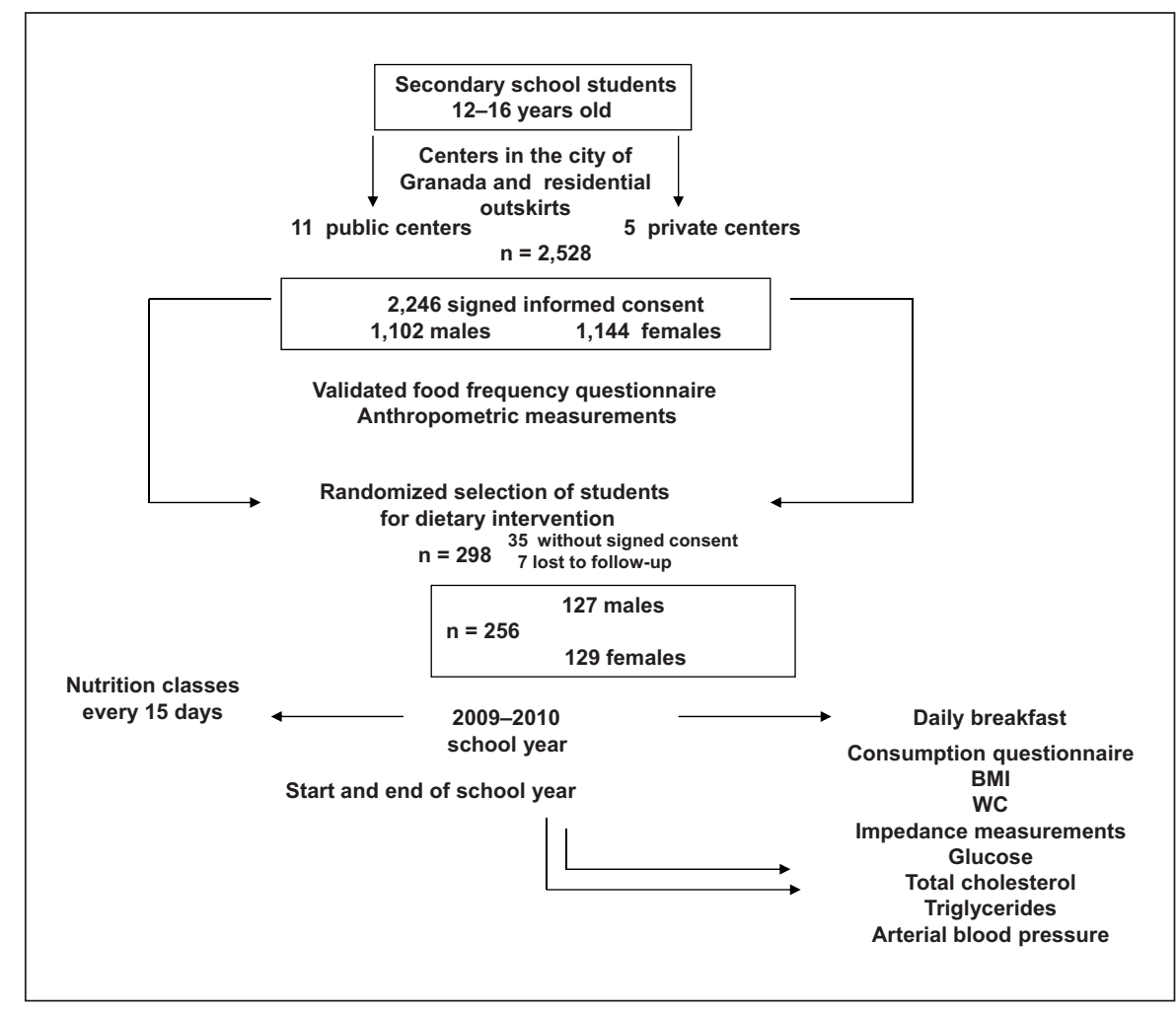

22-32 and 32-42 cm). The mean of three BP readings was used in the analyses.

The students completed a food frequency questionnaire [20] on the daily, weekly, monthly and annual frequency of consumption of 80 items divided among 10 food groups. Energy and macronutrient consumption was calculated from responses using Spanish food composition tables [21].

Following recently published International Diabetes Federation criteria for the 10- to 16-year age group [22], MS was defined by $\mathrm{WC}>90$ th percentile plus the presence of two or more associated factors: triglycerides $>1.7 \mathrm{mmol} / \mathrm{l}(150 \mathrm{mg} / \mathrm{dl}), \mathrm{HDL}-\mathrm{c}<1.03$ $\mathrm{mmol} / \mathrm{l}(40 \mathrm{mg} / \mathrm{dl})$, systolic $\mathrm{BP}>130 \mathrm{~mm} \mathrm{Hg}$ or diastolic $\mathrm{BP}>85$ $\mathrm{mm} \mathrm{Hg}$, glucose $>5.6 \mathrm{mmol} / \mathrm{l}(100 \mathrm{mg} / \mathrm{dl})$ or known type 2 diabetes mellitus. Participants showing some alteration in biochemical data were immediately referred to the Department of Endocrinology for clinical history, physical examination and repeat biochemical study. If glucose levels exceeded $100 \mathrm{mg} / \mathrm{dl}$ in the second determination, a standard oral glucose tolerance test was performed [23]. Based on its results, participants were classified into one of three groups: (i) normal glucose tolerance, fasting plasma glucose (FPG) $<100 \mathrm{mg} / \mathrm{dl}$ and 2 -hour glucose $<140 \mathrm{mg} / \mathrm{dl}$; (ii) impaired fasting glucose, FPG of 100-126 mg/dl and 2-hour glucose $<140 \mathrm{mg} / \mathrm{dl}$, or (iii) impaired glucose tolerance, FPG $<100$ $\mathrm{mg} / \mathrm{dl}$ and 2-hour glucose of 140-199 mg/dl [24].

Figure 1 depicts the protocol followed in the whole series and in the intervention group. The follow-up and adherence to the program were supported by allowing parents of the intervention group to make phone contact with nutrition specialists on any day of the week throughout the school year.

School-Based Nutrition Intervention in Spanish Adolescents
Out of the 263 students in the intervention group with written consent, 7 were lost to the follow-up: 6 because of the impossibility of obtaining a blood sample and 1 because of a history of fish allergy.

\section{Statistical Analysis}

Categorical data were expressed as frequencies and numerical data as means $( \pm S D)$. First and second measurements were compared using Student's t test for paired samples in the case of numerical and McNemar's test in the case of binary data. Intergroup comparisons were done with Student's t test or, if variances were unequal, with Welch's approximation. Associations between variables were assessed using Pearson's correlation coefficient. $p<0.05$ was considered significant. STATA 9.2 was used for the analyses.

\section{Results}

Table 1 shows the prevalence of overweight and obesity in the global sample (representative of adolescents in Granada) and in the intervention group at the beginning of the school year.

At the end of the school year, the percentage of male and female adolescents with overweight or obesity in the intervention group was significantly lower. The prevalence of overweight fell from $31.5 \%$ before to $21.3 \%$ after 
Table 1. Prevalence of overweight and obesity in global and intervention groups before dietary intervention

\begin{tabular}{|c|c|c|c|c|}
\hline & \multicolumn{2}{|l|}{ Global group } & \multicolumn{2}{|l|}{ Intervention group } \\
\hline & males & females & males & females \\
\hline $\mathrm{n}$ & 1,102 & 1,144 & 131 & 132 \\
\hline Age, years & 13.6 & 13.9 & 13.7 & 14.1 \\
\hline $\mathrm{WC}( \pm \mathrm{SD}), \mathrm{cm}$ & $77.2(9.6)$ & $75.9(9.5)$ & $77.94(9.68)$ & $76.9(9.6)$ \\
\hline Overweight (95\% CI), \% & $22.8(20.2-25.3)$ & $15.8(13.7-18.0)$ & $31.5(22.9-39.6)$ & $21.7(14.5-29.4)$ \\
\hline Obesity (95\% CI), \% & $6.7(5.1-8.2)$ & $3.1(2.0-4.1)$ & $7.9(2.7-12.6)$ & $4.7(0.6-8.5)$ \\
\hline
\end{tabular}

Table 2. Impedance measurements before (PRE) and after the intervention (POST) by sex

\begin{tabular}{|c|c|c|c|c|c|c|c|c|c|c|c|c|}
\hline & \multicolumn{2}{|c|}{ Basal metabolism } & \multicolumn{2}{|c|}{ Fat mass, $\%$} & \multicolumn{2}{|c|}{ Fat mass, kg } & \multicolumn{2}{|c|}{ Lean mass, kg } & \multicolumn{2}{|c|}{ Total body water, kg } & \multicolumn{2}{|c|}{ Impedance, $\Omega$} \\
\hline POST & $1,620.58$ & $1,370.76$ & 18.63 & 28.38 & 11.79 & 17.03 & 48.24 & 40.01 & 35.17 & 28.96 & 526.20 & 602.27 \\
\hline $\mathrm{p}$ value & $<0.001$ & NS & NS & NS & NS & NS & $<0.001$ & $<0.001$ & NS & $<0.001$ & NS & NS \\
\hline
\end{tabular}

the intervention in the males $(\mathrm{p}<0.001)$ and from 21.7 to $14 \%$ in the females, respectively $(\mathrm{p}<0.001)$. The prevalence of obesity fell from $7.9 \%$ before to $5.5 \%$ after the intervention in the males $(\mathrm{p}<0.001)$ and from 4.7 to $3.9 \%$ in the females, respectively $(\mathrm{p}<0.001)$.

Table 2 shows the impedance-measured body composition data before and after the intervention. A significant increase in lean mass (before vs. after) was observed in both males (48.24 vs. $47.67 \mathrm{~kg} ; \mathrm{p}<0.001)$ and females (40.01 vs. $39.25 \mathrm{~kg} ; \mathrm{p}<0.001$ ), although being within the normal range for the age group.

Table 3 details anthropometric variables, blood lipid and glucose concentrations, and BP values before and after the intervention. We found significant differences in BMI $(p<0.001)$, total cholesterol and HDL-c $(p<0.001)$ before versus after the intervention in both sexes, in WC $(\mathrm{p}<0.001)$ only in females, and in triglycerides $(\mathrm{p}<$ $0.004)$ and glucose $(\mathrm{p}<0.001)$ only in males. Glucose values $>100 \mathrm{mg} / \mathrm{dl}$ were found in $10.2 \%$ of adolescents before the intervention and in only $1.4 \%$ after the intervention $(\mathrm{p}<0.001)$. Among those with baseline glycemia $>100$ $\mathrm{mg} / \mathrm{dl}, 5.2 \%$ were diagnosed with increased FPG and $3.8 \%$ with impaired glucose tolerance. No student was diagnosed with diabetes. After the intervention, the percentage of students with triglycerides $>150 \mathrm{mg} / \mathrm{dl}$ was significantly lower than before the intervention $(0.8$ vs. $4.7 \%$; $<<0.001$ ) and the percentage with HDL-c $<40 \mathrm{mg} /$ dl was also significantly lower (2.8 vs. $7.0 \%$; $<<0.001)$. No student had systolic BP $\geq 130 \mathrm{~mm} \mathrm{Hg}$ or diastolic $\mathrm{BP} \geq 85$ $\mathrm{mm} \mathrm{Hg}$. The percentage of students with biochemical data suggestive of MS was significantly lower after the intervention (32.2 vs. 19.7\%, p<0.001).

Table 4 shows dairy macronutrient and energy consumption values before and after the intervention by sex. Before the intervention, both sexes showed a lower consumption of carbohydrates and higher consumption of proteins and fats than recommended dietary reference intakes $\left(\mathrm{DRI}_{\mathrm{s}}\right)$ [25]. After the intervention, both sexes had a significant reduction in the total calorie and fat intake $(\mathrm{p}<0.001)$, although it remained above nutritional recommendations; both sexes showed a reduction in saturated fatty acids and cholesterol $(\mathrm{p}<0.001)$. After the intervention, results showed a higher consumption of carbohydrates in both sexes, but the difference only reached significance in the males ( 41.7 vs. $44.5 \%$; p < 0.001$)$ and consumption remained below nutritional recommendations. Protein consumption was lower in both sexes, but the differences did not reach significance.

Based on BMI, the intervention group was divided into normal weight, overweight and obese. Table 5 compares the anthropometric, biochemical and impedanciometric variables obtained before versus after the intervention. After the intervention, BMI and WC significantly decreased in the normal weight and overweight groups 
Table 3. Anthropometric variables, biochemical data and blood pressure values in male and female students before (PRE) and after the intervention (POST)

\begin{tabular}{|c|c|c|c|c|c|c|}
\hline & \multicolumn{3}{|c|}{ Males $(n=127)$} & \multicolumn{3}{|c|}{ Females $(\mathrm{n}=129)$} \\
\hline & PRE & POST & $\mathrm{p}$ value & PRE & POST & $\mathrm{p}$ value \\
\hline BMI & $21.7(3.4)$ & $21.2(3.3)$ & 0.001 & $21.6(3.6)$ & $21.1(3.3)$ & 0.001 \\
\hline $\mathrm{WC}, \mathrm{cm}$ & $77.9(9.6)$ & $77.0(9.7)$ & 0.059 & $76.8(9.6)$ & $74.9(9.4)$ & 0.001 \\
\hline Systolic BP, mm Hg & $108.1(7.9)$ & $109.0(8.0)$ & 0.61 & $106.4(6.8)$ & $107.02(7.2)$ & 0.83 \\
\hline Diastolic BP, mm Hg & $63.3(6.1)$ & $65.4(6.8)$ & 0.73 & $65.4(6.8)$ & $65.6(7.1)$ & 0.63 \\
\hline Total cholesterol, mg/dl & $151.6(27.8)$ & $145.0(26.9)$ & 0.001 & $169.8(26.4)$ & $155.1(32.1)$ & 0.001 \\
\hline Triglycerides, mg/dl & $71.6(41.7)$ & $60.5(27.4)$ & 0.004 & $65.1(26.2)$ & $67.1(35.6)$ & 0.518 \\
\hline HDL-c, mg/dl & $50.3(10.3)$ & $53.3(9.7)$ & 0.001 & $50.9(8.3)$ & $54.2(7.7)$ & 0.001 \\
\hline Glucose, $\mathrm{mg} / \mathrm{dl}$ & $92.4(6.9)$ & $80.5(7.3)$ & 0.001 & $90.4(14.3)$ & $88.5(6.9)$ & 0.222 \\
\hline
\end{tabular}

Values are means $( \pm S D)$.

Table 4. Intake of energy and macronutrients before (PRE) and after the intervention (POST) by sex

\begin{tabular}{|c|c|c|c|c|c|c|}
\hline & \multicolumn{3}{|l|}{ Males $(\mathrm{n}=127)$} & \multicolumn{3}{|c|}{ Females $(\mathrm{n}=129)$} \\
\hline & PRE & POST & $\mathrm{p}$ value & PRE & POST & $\mathrm{p}$ value \\
\hline Daily calorie intake, kcal & $2,780.3(1,062.1)$ & $2,232.2(1,004.7)$ & 0.001 & $2,465.8(701.1)$ & $2,107.7(1,082.5)$ & 0.001 \\
\hline Carbohydrates, \% & $41.7(6.7)$ & $44.5(6.0)$ & 0.001 & $41.1(6.3)$ & $42.1(6.0)$ & 0.093 \\
\hline Proteins, \% & $26.0(7.4)$ & $23.0(6.0)$ & 0.086 & $24.5(6.1)$ & $23.9(7.1)$ & 0.429 \\
\hline Fats, \% & $32.5(5.6)$ & $32.2(6.8)$ & 0.001 & $34.8(6.1)$ & $33.3(5.89)$ & 0.001 \\
\hline Saturated, \% & $7.9(1.7)$ & $7.8(2.0)$ & 0.001 & $7.9(1.9)$ & $7.5(2.0)$ & 0.001 \\
\hline Monounsaturated, \% & $12.9(2.8)$ & $12.7(3.4)$ & 0.032 & $13.5(3.2)$ & $14.3(3.4)$ & 0.032 \\
\hline Polyunsaturated, \% & $3.7(1.4)$ & $3.7(1.6)$ & 0.036 & $3.7(1.4)$ & $4.2(1.6)$ & 0.001 \\
\hline Cholesterol, mg & $440.1(199.0)$ & $392.8(225.1)$ & 0.001 & $390.6(167.8)$ & $368.2(255.5)$ & 0.001 \\
\hline Fiber, $g$ & $20.8(11.0)$ & $24.1(9.2)$ & 0.496 & $20.6(13.2)$ & $23.6(7.4)$ & 0.556 \\
\hline
\end{tabular}

Macronutrients are expressed as percentage of the total caloric value. Values are means $( \pm \mathrm{SD})$.

Table 5. Anthropometric variables, biochemical data and impedance measurements before (PRE) and after the intervention (POST) by BMI

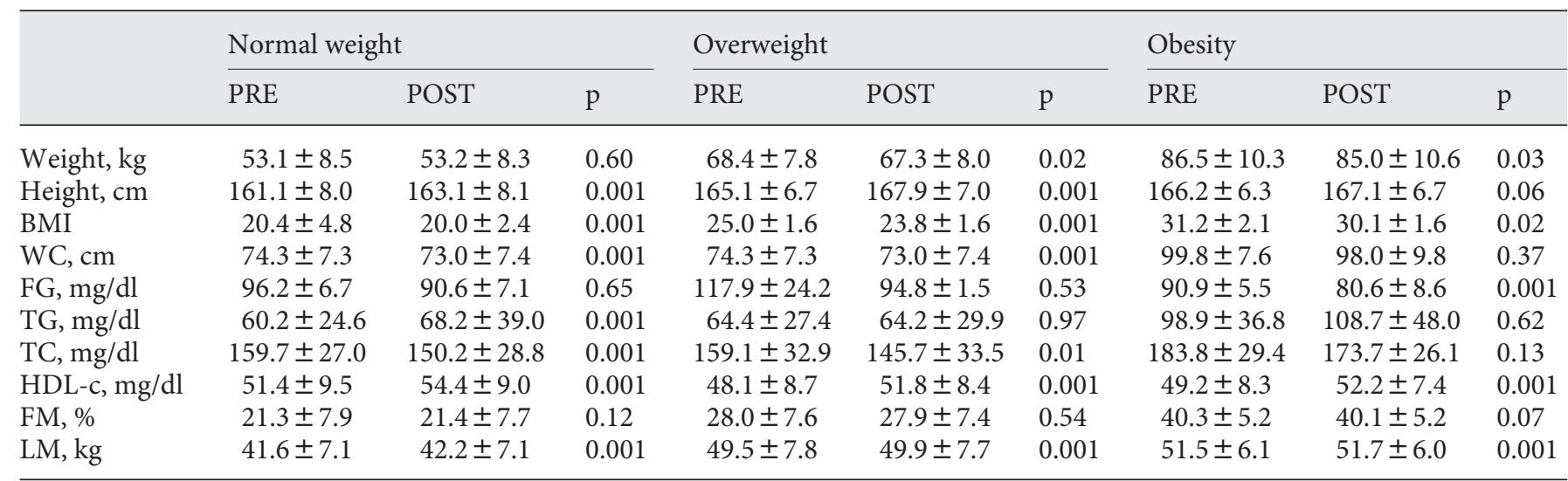

$\mathrm{FG}=$ Fasting glucose $\mathrm{TG}=$ triglycerides $\mathrm{TC}=$ total cholesterol; $\mathrm{FM}=$ fat mass $\mathrm{LM}=$ lean mass. 
$(\mathrm{p}=0.001)$, but only BMI $(\mathrm{p}=0.02)$ decreased in the obese group. Fasting glycemia was significantly lower $(\mathrm{p}=$ 0.001) in the obese group after the intervention. Total cholesterol levels were lower in all three groups: normal weight $(\mathrm{p}=0.001)$, overweight $(\mathrm{p}=0.01)$ and obese $(\mathrm{p}=$ 0.13 ). After educational intervention, there were significant increases in the levels of HDL-c and lean body mass $(\mathrm{p}=0.001)$ in all three groups.

\section{Discussion}

This study reports that a school-based program of nutritional intervention had a positive impact on the food habits, anthropometric and body composition variables, and MS-related biochemical parameters of a population of adolescents in a southern Spanish city.

The alarming finding that $22.8 \%$ of these adolescents (12-16 years old) were overweight and $6.7 \%$ were obese confirms previous reports of an increasing prevalence of overweight and obesity in Spanish children over the past few decades [26]. In two recent studies, EnKid and AVENA, the prevalence of adolescent obesity in Spain was reported to be among the highest in Europe [2, 27]. In fact, the prevalence of overweight in the present series is virtually the same as in Cyprus, which has the highest reported prevalence (23\%) in Europe [28].

A study of an 11- to 14-year-old population in a city in the Basque Country (northern Spain) classified 7.2\% as obese and found a higher prevalence of overweight and obesity among males than females [29]. A study of a younger Spanish population (6-8 years) reported a higher prevalence of overweight (18 vs. $15.7 \%$ ) and obesity (10.5 vs. 9.4\%) among females than males [30].

Our medium-term nutritional intervention program produced a major reduction in the prevalence of overweight and obesity in both sexes. There was a fall in overweight prevalence over the school year of $32.4 \%$ among the males and $35.5 \%$ among the females, and a decrease in obesity prevalence of $30.4 \%$ in the males versus $17 \%$ in the females.

There is no clear published evidence of the efficacy of dietary interventions to prevent childhood or adolescent obesity. However, there has been a marked increase in reports on this type of program, with a growing number of studies in the secondary school setting $[31,32]$.

A meta-analysis [33] examined school-based studies using exercise alone, diet alone or diet plus exercise and found them to be heterogeneous in study design, study population and type of intervention. Significant differ- ences between intervention and control groups were only observed in a study that used diet alone (one of three with this approach), which was a very short-term program [34]. In this investigation, the intervention consisted of the daily administration of breakfast (during the school week) along with information on the importance of a healthy diet, while the control group only received the dietary information. The BMI significantly increased in both sexes in the control group but not in the intervention group. Strengths of our study include the large sample size and the length of the study, which allowed significant changes to be detected in the prevalence of overweight and obesity and in dietary habits. Despite the randomized selection of our global and intervention samples, the prevalence rates of overweight and obesity were higher among the intervention group than among the overall series in both sexes, although their confidence intervals overlapped.

Once the group had been divided into normal weight, overweight and obese, we were able to show that all three groups benefitted from both the weight reduction and the metabolic variables after the application of NEP to the lifestyle changes. The obese group was the least responsive, indicating that it would be necessary to use a more specific intervention program that would unite changes in lifestyle with changes in behavior over a long period of time.

We believe that the educational program aimed at the parents has also been shown to be beneficial, given that the changes in lifestyle should take place inside the family unit and that the teaching of good food habits is a task that parents should undertake seriously, which requires time and concomitant attempts to make it both fun and educational in order to gain the trust and support of their children [35].

Interventions have been found to have different and inconsistent effects on girls and boys. Although the reasons for these differences remain unclear, males and females in this age group may respond distinctly to different elements of interventions [33]. Thus, in the present study, the response to the intervention program was superior in the obese males than in the obese females.

Our medium-term intervention program achieved progress towards our objective of changing dietary habits, with both males and females showing highly significant decreases in the daily calorie and fat intake, although they remained below nutritional recommendations. There were some other minor qualitative changes in the diet, with a significant increase in carbohydrate consumption to $44 \%$ of dairy caloric intake, although this also remained below $\mathrm{DRI}_{\mathrm{s}}$ recommendations. 
Despite producing only a modest change in dietary habits, the NEP achieved striking reductions in BMI and WC levels. The administration of breakfast had apparently a major effect on our intervention. A history of no breakfast is frequently reported in studies of obese children and is considered to predispose children to the consumption of foods with high energetic content midmorning or at lunch $[36,37]$. In our program, the breakfast contributed to an increased intake of fruits. In fact, for some children, it was the first time that their diet included fruit. The change in energy and macronutrient consumption after the intervention is explained by the increased intake of vegetables, legumes and fruits, and the reduced intake of sweets, pastries, cold meats and sugary drinks (soft drinks and bottled juices).

The intervention did not include an exercise program or monitor the children's exercise activities, but the children were repeatedly encouraged in the fortnightly classes to increase their physical exercise and reduce sedentary activities. It should be borne in mind that Spain is among the five most sedentary countries of the European Union [38]. In fact, our results suggest that the adolescents may have increased their physical exercise as a result of the lifestyle recommendations received. The weight loss results were striking given the moderate diet changes achieved, and the weight loss was produced in adipose mass, since both male and female students showed a highly significant increase in lean mass and HDL-c.

Studies of physical exercise programs for adolescents mainly described short-term programs with a small number of participants. Kondo et al. [39] studied a 7 -month aerobic exercise program in young obese females aged 18-23 years and reported a decrease in BMI, leptin, TNF- $\alpha$ and C-reactive protein, with an increase in HDL-c and adiponectin levels (by up to 42\%). Aerobic physical exercise improved sensitivity to insulin even without weight loss in a group of obese girls [40]. Blüher et al. [41] demonstrated that physical training increases circulating levels of adiponectin and the expression of its receptors in skeletal muscle, improving insulin sensitivity and MS components.

The NEP drastically reduced the prevalence of MS in the intervention group from 32 to $19 \%$. Interestingly, although there were students with $5 \%$ prevalence of impaired fasting glucose or $4 \%$ prevalence of impaired glucose tolerance at baseline, none of the study population presented with type 2 diabetes, which may be attributable to the low age of the study population. Recent studies in southern Spain [42] found a 9-35\% prevalence of MS regardless of the definition used.
Garcés et al. [30] studied the lipid profile of younger obese children in Spain and reported elevated triglycerides and cholesterol/HDL-c ratios, and reduced HDL-c and insulin resistance but no changes in glucose levels, which may be related to the chronology of sexual maturation. We did not assess the pubescent stage of our study participants, but a proportion of the children might have been in the prepubertal stage, especially boys. Insulin resistance significantly increases at the beginning of puberty and returns to prepubescent levels at the end of pubescent development $[43,44]$. However, the effects of sex and pubescent stage on the development of insulin sensitivity are not as well differentiated in moderately or severely obese adolescents. It could be argued that a more severe metabolic phenotype would appear at older ages and higher Tanner stages [24].

In conclusion, we believe that our NEP has resulted in beneficial effects, i.e. decreases in overweight, obesity and MS components, in adolescents of both sexes. According to these results, the school can play an important role in health promotion and should offer dietary and nutritional education to pupils from a young age.

\section{Acknowledgments}

This study was supported by grants from the Metabolic Unit Group (No. 541 A 609/193), Granada University and Caja Rural Foundation (Granada, Spain).

\section{Disclosure Statement}

The authors have no conflicts of interest to disclose.

\begin{tabular}{|c|c|c|}
\hline References & $\nabla_{2}$ & $\begin{array}{l}\text { World Health Organization: The challenge } \\
\text { of obesity in Europe. World wide web } 2007 . \\
\text { [WWW document]. URL http://www.euro- } \\
\text { ro.who.int/document/E90711.pdf (accessed } \\
\text { July 2008). } \\
\text { Serra-Majem L, Ribas L, Aranceta J, Pérez C, } \\
\text { Saavedra P, Pena L: Childhood and adoles- } \\
\text { cent obesity in Spain. Results of the EnKid } \\
\text { study (1998-2000). Med Clin (Barc) 2003; } \\
\text { 121:725-732. } \\
\text { Pearson TJ, Power C, Logan S, Summerbell } \\
\text { CD: Childhood predictors of adult obesity: a } \\
\text { systematic review. Int J Obes 1999;23(suppl } \\
\text { 12):S1-S10. } \\
\text { Baker J, Olsen L, Sorensen T: Childhood } \\
\text { body mass index and the risk of coronary } \\
\text { heart disease in adulthood. N Engl J Med } \\
\text { 2007;357:2329-2337. }\end{array}$ \\
\hline
\end{tabular}

Ann Nutr Metab 2012;61:281-288 
5 Gunnell DJ, Frankel SJ, Nanchachal K, Peters TJ, Davey Smith G: Childhood obesity and adult cardiovascular mortality: a 57-y follow-up study based on the Boyd Orr cohort. Am J Clin Nutr 1998;67:1111-1118.

-6 Cook S, Weitzman M, Asinger P, Nguyen M, Dietz WH: Prevalence of a metabolic syndrome phenotype in adolescents: findings from the third National Health and Nutrition Examination Survey. 1988-1994. Arch Pediatr Adolesc Med 2003;157:821-827.

7 Duncan G, Li S, Zhon X: Prevalence and trends of a metabolic syndrome phenotype among U.S. adolescents, 1999-2000. Diabetes Care 2004;27:2438-2443.

8 Ruiz J, Rizzo S, Ortega FB, Loit HM, Veidebaum T, Sjostrom M: Markers of insulin resistance are associated with fatness and fitness in school-aged children: the European Youth Heart Study. Diabetología 2007;50: 1401-1408.

-9 Juonala M, Magnussen C, Berenson G, Venn A, Burns T, Sabin M, Srinivasan S, Daniels S, Davis P, Chen W, Sun C, Cheung M, Viikari J, Dwyer T, Raitakari O: Childhood adiposity, adult adiposity, and cardiovascular risk factors. N Engl J Med 2011;365:1876-1885.

10 Danielzik S, Pust S, Muller MJ: School-based interventions to prevent overweight and obesity in prepubertal children: process and 4 years outcome evaluation of the Kiel Obesity Study (KOPS). Acta Paediatr Suppl 2007; 96:19-25.

11 van Stralen MM, Yildirim M, te Velde SJ, Brug J, van Mechelen W, Chinapaw MJ, ENERGY-consortium: What works in schoolbased energy balance behaviour interventions and what does not? A systematic review of mediating mechanisms. Int J Obes (Lond) 2011;35:1251-1265.

12 Vereecken C, De Henauw S, Maes L, Moreno L, Manios Y, Phillipp K, Plada M, De Bourdeaudhuij I, Helena Study Group: Reliability and validity of a healthy diet determinants questionnaire for adolescents. Public Health Nutr 2009;12:1830-1838.

13 International Physical Activity Questionnaire (IPAQ) http:/www.ipaq.ki.se.

14 Biró G, Hulshof KFAM, Ovesen L, Amorin Cruz JA, EFCOSUM Group: Selection of methodology to assess food intake. Eur J Clin Nutr 2002;56(suppl 2):S25-S32.

15 Cole TJ, Bellizzi MC, Flegal KM, Dietz NH: Establishing a standard definition for child overweight and obesity worldwide: international survey. BMJ 2000;320:1240-1243.

16 Norton K, Olds T: Anthropometrica. Sydney, University of NSW Press, 1996.

17 Bioelectrical impedance analysis in body composition measurement. National Institutes of Health Technology Assessment Conference Statement. Am J Clin Nutr 1996 64(suppl 3):524S-532S

18 Ricciardi R, Talbot L: Use of bioelectrical impedance analysis in the evaluation, treatment, and prevention of overweight and obesity. J Am Acad Nurse Pract 2007;19:235-241.
9 El Assaad MA, Topouchian JA, Asuma RG: Evaluation of two devices for self-measurement of blood pressure according to the international protocol: the Omron M5-I and the Omron 705IT. Blood Press Monit 2003; 8:127-133.

20 Martin-Moreno JM, Boyle P, Gorgojo L, Maisonneuve P, Fermandez-Rodriguez JC, Salvini S, Willet WC: Development and validation of a food frequency questionnaire in Spain. Int J Epidemiol 1993;22:512-519.

21 Mataix J, Mañas M (eds): Tabla de composición de alimentos españoles. Granada, Universidad de Granada, 1998.

22 Zimmet P, Alberti G, Kaufman F, Taima N, Silink M, Arslanian S, Wong G, Bennett P, Shaw J, Caprio S, International Diabetes Federation Task Force on Epidemiology and Prevention of Diabetes: The metabolic syndrome in children and adolescents. Lancet 2007;369:2059-2061.

23 Weiss R, Dufour S, Taksali SE, Tamborlane WV, Petersen KF, Bonadonna RC, Boselli L, Barbetta G, Allen K, Rife F, Savoye M, Dziura J, Sherwin R, Shulman G, Caprio S: Prediabetes in obese youth: a syndrome of impaired glucose tolerance, severe insulin resistance and altered myocellular and abdominal fat partitioning. Lancet 2003;362: 951-957.

24 Cali AM, Bonadonna RC, Trombeta M, Weiss R, Caprio S: Metabolic abnormalities underlying the different prediabetic phenotypes in obese adolescents. J Clin Endocrinol Metab 2008;93:1767-1773.

25 United States Department of Agriculture: Food and Nutrition Information Center. Dietary Guidance: Dietary Reference Intakes. http://fnic.nal.usda.gov/dietary-guidance/ dietary-reference-intakes.

26 Moreno LA, Sarria A, Fleta J, Rodriguez G, Bueno M: Trends in body mass index and overweight prevalence among children and adolescents in the region of Aragon (Spain) from 1985 to 1995. Int J Obes Relat Metab Disord 2000;24:925-931.

-27 Moreno LA, Mesana MI, Fleta J, Ruiz JR, González-Gross MM, Sarriá A, Marcos A, Bueno M, AVENA Study Group: Overweight, obesity and body fat composition in Spanish adolescents. The AVENA study. Ann Nutr Metab 2005;49:71-76.

28 Lobstein T, Frelut ML: Prevalence of overweight among children in Europe. Obes Rev 2003;4:195-200.

-29 Larrañaga N, Amiano P, Arrizabalaga JJ, Bidaurrazaga J, Gorostiza E: Prevalence of obesity in 4-18-year-old population in the Basque Country, Spain. Obes Rev 2007;8: 281-287.

30 Garcés C, Gutierrez Guisado J, Benavente M, et al: Obesity in Spanish schoolchildren: relationship with lipid profile and insulin resistance. Obes Res 2005;6:959-963.

31 Foster G, Sherman S, Borradaile K, Grundy K, Vander Veur S, Nachmani J, Karpyn A, Kumanyika S, Shults J: A policy-based school intervention to prevent overweight and obesity. Pediatrics 2008;121:e794-e802.

32 Durant N, Baskin ML, Thomas O, Allison DB: School-based obesity treatment and prevention programs: all in all, just another brick in the wall? Int J Obes 2008;32:17471751.

33 Brown T, Summerbell C: Systematic review of school-based interventions that focus on changing dietary intake and physical activity levels to prevent childhood obesity: an update to the obesity guidance produced by the National Institute for Health and Clinical Excellence. Obes Rev 2009;10:110-141.

34 Ask AS, Hernes S, Aarek I, Johannessen G, Haugen M: Changes in dietary pattern in 15 year old adolescents following a 4 month dietary intervention with school breakfast - a pilot study. Nutr J 2006;5:33-41.

35 Sociedad Española Nutrición Comunitaria (eds): Guía de la alimentación saludable. SENC, Madrid, 2004.

-36 Moreno LA, Rodríguez G: Dietary risk factors for development of childhood obesity. Curr Opin Clin Nutr Metab Care 2007;10: 336-341.

37 Serra-Majem L, Aranceta J, Pérez C, Ribas L, Delgado A: Prevalence and determinants of obesity in Spanish children and young people. Br J Nutr 2006;96(suppl):67-72.

38 Varo JJ, Martínez-González MA, De IralaEstévez J, Kearney J, Gibney M, Martínez JA: Distribution and determinants of sedentary lifestyles in the European Union. Int J Epidemiol 2003;32:138-146.

39 Kondo T, Kobayashi I, Murakami M: Effect of exercise on circulating adipokine levels in obese young women. Endocr J 2006;53:189195

40 Nassis GP, Papantakon K, Skender K, Triandagillopoulou K, Yannakoulia M, Chrousos G, Sidossis L: Aerobic exercise training improves insulin sensitivity without changes in body weight, body fat, adiponectin and inflammatory markers in overweight and obese girls. Metabolism 2005;54:1472-1479.

41 Blüher M, Bullen J, Lee J, Kralisch S, Fasshaver M, Kloting N, Niebaner J, Schon M, Willians C, Mantzores Ch: Circulating adiponectin and expression of adiponectin receptors in human skeletal muscle: associations with metabolic parameters and insulin resistance and regulation by physical training. J Clin Endocrinol Metab 2006;91:2310-2316.

-42 Olza J, Gil-Campos M, Leis R, Bueno G, Aguilera C, Valle M, Cañete R, Tojo R, Moreno L, Gil A: Presence of the metabolic syndrome in obese children at prepubertal age. Ann Nutr Metab 2011;58:343-350.

43 Moran A, Jacobs DR, Steinberger J, Hong C, Prineas R, Luepker R, Sinaiko AR: Insulin resistance during puberty: results from clamp studies in 357 children. Diabetes 1999; 48:2039-2044.

44 Goran MI, Gower BA: Longitudinal study on pubertal insulin resistance. Diabetes 2001; 50:2444-2450. 